\title{
Expression of FAP- I by human colon adenocarcinoma: implication for resistance against Fas-mediated apoptosis in cancer
}

\author{
H Yao',4, E Song ${ }^{2,4}$, J Chen' and P Hamar,3 \\ 'Department of Oncology, Sun-Yat-Sen Memorial Hospital, Guangzhou, People's Republic of China; ${ }^{2}$ Department of Surgery, Sun-Yat-Sen Memorial \\ Hospital, Guangzhou, People's Republic of China; ${ }^{3}$ Institute of Pathophysiology, Department of Medicine, Semmelweis University, Nagyvárad tér 4 , \\ Budapest H-1089, Hungary
}

Although colon carcinoma cells express Fas receptors, they are resistant to Fas-mediated apoptosis. Defects within the intracellular Fas signal transduction may be responsible. We investigated whether the Fas-associated phosphatase-I (FAP-I), an inhibitor of Fas signal transduction, contributed to this resistance in colon carcinomas. In vivo, apoptosis of cancer cells was detected in situ using terminal deoxynucleotidyltransferase-mediated dUTP nick-end labelling (TUNEL). FAP-I, FasR, and Fas ligand (FasL) were detected using immunohistochemistry. In vitro, colon carcinoma cells were primarily cultured, and their sensitivity to Fas-mediated apoptosis was evaluated by treatment with agonistic anti-FasR CHI I IgM monoclonal antibody in the presence or absence of synthetic Ac-SLV (serine-leucine-valine) tripeptide. Fas-associated phosphatase-I expression was detected in 20 out of 28 colon adenocarcinomas. In vivo, a positive correlation between the percentage of apoptotic tumour cells and the number of FasL-positive tumour infiltrating lymphocytes was observed in FAP-I negative cancers, but not in FAP-I-positive ones. Primarily cultured colon cancer cells, which were refractory to $\mathrm{CH}$ - I I-induced apoptosis, had higher expression of FAP-I on protein and mRNA levels than the sensitive group. Resistance to Fas-mediated apoptosis in tumour cells could be abolished by Ac-SLV tripetides. Fas-associated phosphatase- I expression protects colon cancer cells from Fas-mediated apoptosis, and blockade of FAP-I and FasR interaction sensitises tumour cells to Fas-dependent apoptosis.

British Journal of Cancer (2004) 9 I, 17I8-1725. doi:10.1038/sj.bjc.6602I36 www.bjcancer.com

Published online 19 October 2004

(c) 2004 Cancer Research UK

Keywords: Fas-associated phosphatase-I; Fas receptor; colon neoplasms; apoptosis; immune escape

Despite the presence of tumour-specific cytotoxic T lymphocytes (CTLs) and natural killer (NK) cells, the immune system fails to contain colon cancers. These malignancies are able to escape immune clearance, and are resistant to cytotoxic activities of host immunonocytes (Halapi, 1998; Beatty and Paterson, 2000; Song et al, 2001a). However, the exact mechanisms by which colon cancer cells escape CTL or NK cell-mediated destruction remain poorly understood.

The Fas-Fas ligand (FasL) interacting system has been recognised as a major pathway for CTL- and NK cell-mediated apoptotic cell death (Kägi et al, 1994; Lowin et al, 1994; Arase et al, 1995). When CTLs or NK cells recognise target cells, they become activated and express FasL, which binds to Fas receptors on the surface of the target cells and induce target cell apoptosis (Leithauser et al, 1993; Suda et al, 1993; Suda and Nagata, 1994; Nagata, 1997). Upon contact with crosslinking anti-Fas antibodies or FasL, the Fas-bearing cells rapidly undergo apoptosis. Although colon cancer cells abundantly express Fas receptors at mRNA and protein level, they are insensitive to FasR-mediated apoptosis

\footnotetext{
*Correspondence: Dr P Hamar; E-mail: hampet@net.sote.hu

${ }^{4}$ The first two authors contributed equally to this work

Received 25 February 2004; revised 13 July 2004; accepted 20 July 2004; published online 19 October 2004
}

(Leithauser et al, 1993; O'Connell et al, 1998; Grosch et al, 2001; Vermijlen et al, 2001).

The resistance of most colon cancer cells to FasL-induced apoptosis may explain their capability to escape immune cytolysis (Tillman et al, 1998; von Reyher et al, 1998). However, the molecular mechanisms of this process are still unknown. Some authors suggest that the FasR resistance of colon cancer cells is based on defects of intracellular Fas signal transduction (O'Connell et al, 1998; Vermijlen et al, 2001).

Fas-associated phosphatase-1 (FAP-1) is a tyrosine phosphatase, which intracellularly inhibits FasR-mediated apoptosis. By interacting with the cytoplasmic death domain of Fas receptors, FAP-1 acts as a negative switch in the Fas pathway. Introduction of FAP-1 into Fas-sensitive cells blocks FasL-induced apoptosis (Ungefroren et al, 2001). Furthermore, FAP-1 overexpression correlates with the resistance of some human malignant cells to Fas-mediated apoptosis, such as pancreatic cancer cells, hepatoblastoma cells, leukaemia T cells and AIDS-associated Kaposi's sarcoma cells (Lee et al, 1999a).

In a multistep oral carcinogenesis model, the expression of FAP-1 increased in parallel to the progression towards malignancy (Itakura et al, 2000). On the other hand, spontaneous downregulation of FAP-1 expression contributes to the excessive apoptosis of haematopoietic cells in myelodysplastic syndromes (Bernhard et al, 2001). Furthermore, interruption of the 
conjugation between FasR and FAP-1 by a synthetic SerineLeucine-Valine (Ac-SLV) tripeptide abolished the resistance to FasR-mediated apoptosis in human thymocytes (Song et al, 2001b). Thus, it is clear that FAP-1 plays an essential regulatory role in Fas-mediated apoptosis. However, although colon cancers have been found to express FAP-1, its contribution to Fas resistance has not been determined.

Therefore, the present study examined the expression of FAP-1 in colon cancer cells, and investigated whether FAP-1 contributed to the resistance of colon cancer against FasR-mediated apoptosis.

\section{MATERIALS AND METHODS}

\section{Patients and tissue samples}

Tissue samples of human colon adenocarcinomas from 28 patients were collected, with informed consent, after surgical resections performed at Sun-Yat-Sen University of Medical Science, Guangzhou, following a protocol approved by the University Teaching Hospitals ethics committee. None of the patients had received chemo-, radio-, or immuno-therapy before resection. Tumours were well $(n=9)$, moderately $(n=11)$, and poorly $(n=8)$ differentiated including three cases of mucinous adenocarcinomas. Pathological staging followed the rules of the Dukes system, with seven cases of Dukes A $\left(\mathrm{T}_{1} \mathrm{~N}_{0} \mathrm{M}_{0}\right.$ : mucosa only), 12 cases of Dukes $\mathrm{B}\left(\mathrm{T}_{2} \mathrm{~N}_{0} \mathrm{M}_{0}\right.$ : into but not through the muscularis propria) and nine cases of Dukes $C\left(\mathrm{~T}_{n} \mathrm{~N}_{1} \mathrm{M}_{0}\right.$ : locally positive nodes). None of the cases was found to have metastases to distal organs. Tissue samples were used in part for primary cell cultures. The rest was snap frozen in liquid nitrogen and stored at $-80^{\circ} \mathrm{C}$ for immunohistochemical staining.

\section{Immunohistochemistry}

A polyclonal antibody for Fas (C20; dilution 1/50), a polyclonal antibody for FasL (N20; dilution 1/50), and a polyclonal antibody for FAP-1 (C20; dilution 1/50) were obtained from Santa Cruz Biotechnology (Santa Cruz, CA, USA). A monoclonal antibody for leucocyte common antigen CD45 (clone 2B11 + PD7/26; dilution 1/ 70) for the identification of tumour infiltrating lymphocytes (TILs) and a labelled streptavidin-biotin (LSAB) immunohistochemical detection kit were obtained from Dako Corp. (Carpinteria, CA).

Acetone-fixed consecutive cryostat tissue sections $(4 \mu \mathrm{m})$ of colon cancers were stained immunohistochemically with the above antibodies according to the standard LSAB staining techniques. Briefly, endogenous peroxidase activity was quenched by incubation with $3.0 \%$ hydrogen peroxide in methanol for $5 \mathrm{~min}$. Sections were washed in phosphate-buffered saline (PBS) and blocked for $1 \mathrm{~h}$ in a washing buffer containing $5 \%$ normal goat serum (Sigma Chemical Co, St Louis, MO, USA). The primary antibody was added for incubation overnight at $4^{\circ} \mathrm{C}$. After washing in PBS, the sites of primary antibody binding were localised by sequential incubation with biotinylated goat anti-rabbit antibody and then streptavidin conjugated with horseradish peroxidase. After further washing in PBS, diaminobenzidine (DAB; Dako Corp., Carpinteria, CA, USA) was used as a chromogen and sections were lightly counterstained with haematoxylin. As negative controls for Fas, FasL, and FAP-1, the immunising peptide to which the antibodies were raised (Dako Corp. Carpinteria, CA, USA) were added at $1 \mu \mathrm{g} \mathrm{ml}^{-1}$ to the primary antibody as a direct, internal competitive control. As a negative control for CD45, we used nonimmune mouse serum instead of the CD45 monoclonal antibody.

\section{Assessment of FasL-positive TILs}

Tumour infiltrating lymphocytes were identified by CD45 staining in consecutive sections, and those that were adjacent to tumour nests were counted for positive immunohistochemical staining of
FasL under high-power microscopy $(\times 400$, more than 30 fields counted per section). The view fields for cell counting were chosen according to a systematic random sampling method. FasL-positive TILs were expressed as cells per field of view (c/FV).

\section{Detection of in situ cell death by terminal deoxynucleotidyltransferase-mediated dUTP nick-end labelling (TUNEL)}

Cell death was detected in situ in resected tissues by enzymatic labelling of DNA strand breaks with a TUNEL assay (Boehringer Mannheim GmbH, Mannheim, Germany) according to the manufacturer's instructions. Cryostat sections were treated with proteinase $\mathrm{K}\left(20 \mu \mathrm{g} \mathrm{ml}^{-1}\right.$ in $10 \mathrm{~mm}$ Tris/HCl, pH 7.6) for $30 \mathrm{~min}$. After washing, peroxidase block was similar to that described above. The samples were permeabilised $(0.1 \%$ Triton $\mathrm{X}-100$ in $0.1 \%$ sodium citrate $15 \mathrm{~min})$. For the labelling reaction, a TdT buffer solution (composition: potassium cacodylate $100 \mathrm{mmoll}^{-1}$; cobalt chloride $2 \mathrm{mmoll}^{-1}$; dithiothreitol $0.2 \mathrm{mmoll}^{-1}$; $\mathrm{pH} 7.2$ ) containing $0.3 \mathrm{U}^{-1} \mathrm{l}^{-1}$ biotinylated dUTP was added to cover the sections, incubated at $37^{\circ} \mathrm{C}$ for $60 \mathrm{~min}$ in a humidified chamber. TdT was omitted from negative control slides. To localise cells containing labelled DNA strand breaks, sections were washed and incubated with peroxidase-labelled streptavidin for $30 \mathrm{~min}$, and were finally stained with $\mathrm{DAB}$ solutions, followed by counterstaining with haematoxylin. Approximately 1000 colon cancer cells were counted under high-power microscopy $(\times 400)$ and the percentage of TUNEL-positive tumour cells with apoptotic morphology was calculated.

\section{Primary cell culture of colon cancer}

Cell suspensions derived from tumour samples were obtained by enzymatic digestion with medium containing $0.1 \%$. collagenase type IA, $0.002 \%$ DNase type II and $0.05 \%$ protease type I (Sigma Chemical Co, St Louis, MO, USA). Tumour cells were isolated by adherence to plastic culture vessels for $36 \mathrm{~h}$ in a $5 \% \mathrm{CO}_{2}$ incubator at $37^{\circ} \mathrm{C}$. Supernatants were discarded and tumour cells were cultured in RPMI 1640 supplemented with 10\% FCS in a humidified $5 \% \mathrm{CO}_{2}$ atmosphere. Assessment of tumour cells was performed by light microscopy, electronic microscopy and immunohistochemistry for keratin.

\section{Assessment of anti-FasR mAb CH11-induced apoptosis}

Sensitivity of primarily cultured colon cancer cells to Fas-mediated apoptosis was determined by treatment with the agonistic antiFasR CH11 IgM monoclonal antibody (Kamiya Biomedical Co, Thousand Oaks, CA, USA) at concentrations of 10, 100, 500, and $1000 \mathrm{ng} \mathrm{ml}^{-1}$, or isotype control IgM (Kamiya) at a concentration of $1000 \mathrm{ng} \mathrm{ml}^{-1}$. In some experiments, cells were pretreated with $20 \mathrm{~mm}$ of synthetic Ac-SLV tripeptide (Calbiochem-Novabiochem, La Jolla, CA, USA), an inhibitor of FAP-1, for $12 \mathrm{~h}$, and were subsequently incubated with anti-FasR CH11 MoAb.

After $24 \mathrm{~h}$ of incubation, the number of apoptotic primarily cultured colon cancer cells was determined by TUNEL assay (Boehringer Mannheim $\mathrm{GmbH}$ ) and flow cytometry. Briefly, $1 \times 10^{6}$ cells were washed in PBS and permeabilised with $0.1 \%$ Triton X-100 in $0.1 \%$ sodium citrate solution on ice for $5 \mathrm{~min}$. Cells were washed again and incubated for $60 \mathrm{~min}$ at $37^{\circ} \mathrm{C}$ in a labelling TUNEL reaction mixture containing TdT reaction buffer $(10.0 \mu \mathrm{l})$, Br-dUTP $(8.0 \mu \mathrm{l}), \mathrm{dH}_{2} \mathrm{O}(32.25 \mu \mathrm{l})$, and $\mathrm{TdT}(0.75 \mu \mathrm{l})$. The reaction was then terminated by the addition of a rinse buffer. Cells were washed before resuspension in $0.1 \mathrm{ml}$ of rinse buffer. Incorporated Br-dUTP was detected after the addition of fluorescein-labelled anti-bromodeoxyuridine antibody $(5.0 \mu \mathrm{l})$ and incubation for $30 \mathrm{~min}$ at room temperature in darkness. Flow cytometric analysis 
was performed with a FACScan flow cytometer with LYSIS II software (Nippon Becton Dickinson, Tokyo, Japan).

\section{Immunofluorescence analysis for FAP-1}

After harvesting by scraping, $1 \times 10^{6}$ primarily cultured colon cancer cells were washed with PBS and fixed with $1 \%$ formaldehyde for $15 \mathrm{~min}$ on ice. Fixed cells were centrifuged, resuspended in PBS and mixed 1:10 with ice-cold $70 \%$ ethanol to solubilise membranes. Then, cells were incubated with $10 \mu \mathrm{g} \mathrm{ml}^{-1}$ polyclonal goat anti-human FAP-1 antibody (Santa Cruz Biotechnology) for $30 \mathrm{~min}$ at $4{ }^{\circ} \mathrm{C}$ and washed in PBS. Fluorescein-conjugated anti-goat IgG, as secondary antibody (Dako Corp., Carpinteria, CA), was added to the cells for $30 \mathrm{~min}$ at $4^{\circ} \mathrm{C}$. Cells were washed again in PBS and the intensity of fluorescence was analysed with FACScan flow cytometer and LYSIS II software (Nippon Becton Dickinson, Tokyo, Japan). An isotype-matched control antibody was used to determine nonspecific binding. A total of 10000 cells were examined for each evaluation. Data were expressed as relative fluorescence intensity (RFI = mean fluorescence intensity of cells stained with anti-FAP-1 Ab/mean fluorescence intensity of cells stained with control $\mathrm{Ab}$ ).

\section{RT - PCR detection of FAP-1}

RNA was isolated from primarily cultured colon cancer cells by lysis in guanidine thiocyanate (Sigma Chemical Co, St Louis, MO, USA) followed by phenol extraction and ethanol precipitation. cDNA was synthesised from $2 \mu \mathrm{g}$ of total isolated RNA in a $20 \mu \mathrm{l}$ reaction mixture containing $4 \mu \mathrm{l}$ of $5 \times \mathrm{RT}$ reaction buffer, $10 \mathrm{U}$ of Rnasin (Promega Corp., Madison, WI, USA), $200 \mu \mathrm{M}$ deoxynucleotide triphosphate, $40 \mathrm{pm}$ oligodeoxythymidylic acid primer, and $20 \mathrm{U}$ of Moloney murine reverse transcriptase (Promega). The mixture was incubated at $42^{\circ} \mathrm{C}$ for $1 \mathrm{~h}$ and then incubated at $53^{\circ} \mathrm{C}$ for $30 \mathrm{~min}$. The unhybridised RNA was then digested with $10 \mathrm{U}$ of Rnase $\mathrm{H}$ at $37^{\circ} \mathrm{C}$ for $10 \mathrm{~min}$.

PCR was performed on cDNA using primers (sense and antisense) for the amplification of FAP-1 and a house-keeping gene, $\beta$-actin. The primers were designed according to published sequences: FAP-1, (sense) 5'-AGGTCTGCAGAGAAGCAAGAATAC$3^{\prime}$ and (antisense) $5^{\prime}$-GAATACGAGTGTCAGACATGG-3' (Irie et al, 2001); $\beta$-actin, (sense) $5^{\prime}$-ACTACCTCATGAAGATCCTCA- $3^{\prime}$ and (antisense) 5'-CAGGAGGAGCAATGATCTTGA-3'(Irie et al, 2001).

Thermal cycling was performed as follows: denaturation at $94^{\circ} \mathrm{C}$ for $1 \mathrm{~min}$, annealing at $55^{\circ} \mathrm{C}$ for $1 \mathrm{~min}$, and extension at $72^{\circ} \mathrm{C}$ for 1 min. In all, 30 cycles were performed for the FAP-1 PCR and 28 cycles for the $\beta$-actin PCR. Primers were used at a final concentration of $0.1 \mu \mathrm{M}$ each, dNTPs at $50 \mu \mathrm{M}, \mathrm{MgCl}_{2}$ at $1.5 \mathrm{~mm}$, Taq DNA polymerase at $1.0 \mathrm{U}$ per $50 \mu \mathrm{l}$ reaction. PCR products of 607 and $762 \mathrm{bp}$ were predicted for FAP- 1 and $\beta$-actin, respectively. PCR products were separated by electrophoresis in $2 \%$ agarose gels and stained with ethidium bromide. The target bands were analysed densitometrically by using a GS-700 Imaging Densitometer (BioRad, Hercules, CA, USA). Fas-associated phosphatase1 cDNA was semiquantitated by densitometric comparison with $\beta$ actin from the same sample.

\section{Statistical analysis}

All experiments for cell cultures were performed at least three times. The results are described as mean \pm standard deviation. Statistical analysis was performed by one-way analysis of variance and comparisons among groups were performed by independent sample $t$-test or Bonferroni's multiple-comparison $t$-test. To examine the correlation between the number of FasL-positive TILs and the percentage of in situ apoptotic colon cancer cells, log transformation was performed on the former data, which allowed statistical analysis of a linear relationship between the two variables by calculating the Pearson's correlation coefficient. A two-tailed $P$-value less than 0.05 was considered to be statistically significant.

\section{RESULTS}

\section{Immunohistochemical analysis of FAP-1, FasR, and FasL}

The immunostaining with each antibody was judged to be antibody specific by using the immunising peptide for each antibody as an internal control. Inclusion of the soluble peptide immunogen during immunohistochemistry resulted in direct competitive displacement of positive staining in consecutive control sections.

By immunohistology, FAP-1 was present in 20 out of 28 cases (71.4\%) of colon adenocarcinomas. Fas-associated phosphatase-1 was primarily localised in carcinoma cells, rather than in infiltrating lymphocytes. Fas-associated phosphatase- 1 was located primarily in the cytoplasm and along the cell membrane, while nuclei were clearly negative (Figure 1A). Fas-associated phosphatase-1-positive cells were randomly distributed within a section. Intensity of immunostaining varied from weak to intense in neoplastic areas, both within individual tumours and among tumours, and was independent of histological type and staging of the cancer.

In contrast, FasR was present in all colon adenocarcinomas tested (Figure 1B). Extent and intensity of the staining did not vary among different tumour staging or histological types, and did not correlate to the percentage of TUNEL-positive tumour cells.

As demonstrated by CD45 immunohistochemical staining, all 28 carcinomas were infiltrated by immunocytes with lymphoid morphology. In all cases of colon carcinomas, FasL immunostaining was observed in tumour infiltrating lymphocytes (TILs) that had been identified by CD45 staining in consecutive sections (Figure 1C). The number of FasL-positive TILs observed under high-power microscopy did not correlate with cancer staging or differentiation. Tumour cells were FasL positive in 17 out of 28 $(60.7 \%)$ colon carcinomas (not shown).

\section{Apoptosis of colon cancer cells}

TUNEL-positive cancer cells were randomly distributed in tumour nests and were accompanied by morphological signs of apoptosis, such as chromatin condensation, detachment of the cytoplasm from the environment and formation of apoptotic bodies (Figure 1D). TUNEL staining was also observed in TILs near or distal to tumour nests.

In colon cancers with negative FAP-1 immunostaining $(n=8)$, a linear correlation was observed between the percentage of apoptotic cancer cells and the log value of Fas-positive cell counts of TILs $(r=0.835, P<0.01$; Figure $2 \mathrm{~A})$. In contrast, in FAP-1positive colon carcinomas $(n=20)$, no correlation was observed between apoptosis of cancer cells and FasL expression in TILs (Figure 2B). Additionally, the percentage of apoptotic cancer cells was lower in colon cancers with positive FAP-1 immunostaining than in FAP-1-negative tumours $(4.0 \pm 1.2$ vs $5.9 \pm 1.7 ; P<0.05)$. However, apoptosis of colon cancer cells did not vary with tumour stage or differentiation.

\section{Fas-mediated apoptosis in primarily cultured cancer cells}

To further evaluate the sensitivity of colon cancer cells to FasRmediated apoptosis, primarily cultured tumour cells from each resected sample were individually treated with agonistic anti-Fas $\mathrm{MoAb} \mathrm{CH}-11$. Purity of isolated cancer cells, as assessed by light microscopy, electronic microscopy and immunohistochemistry for keratin, was more than $97 \%$ in each case (not shown). After incubation for $24 \mathrm{~h}$ in the presence of $\mathrm{CH}-11$ at concentrations of up to $500 \mathrm{ng} \mathrm{ml}^{-1}$, a dose-dependent increase of apoptotic cells was 

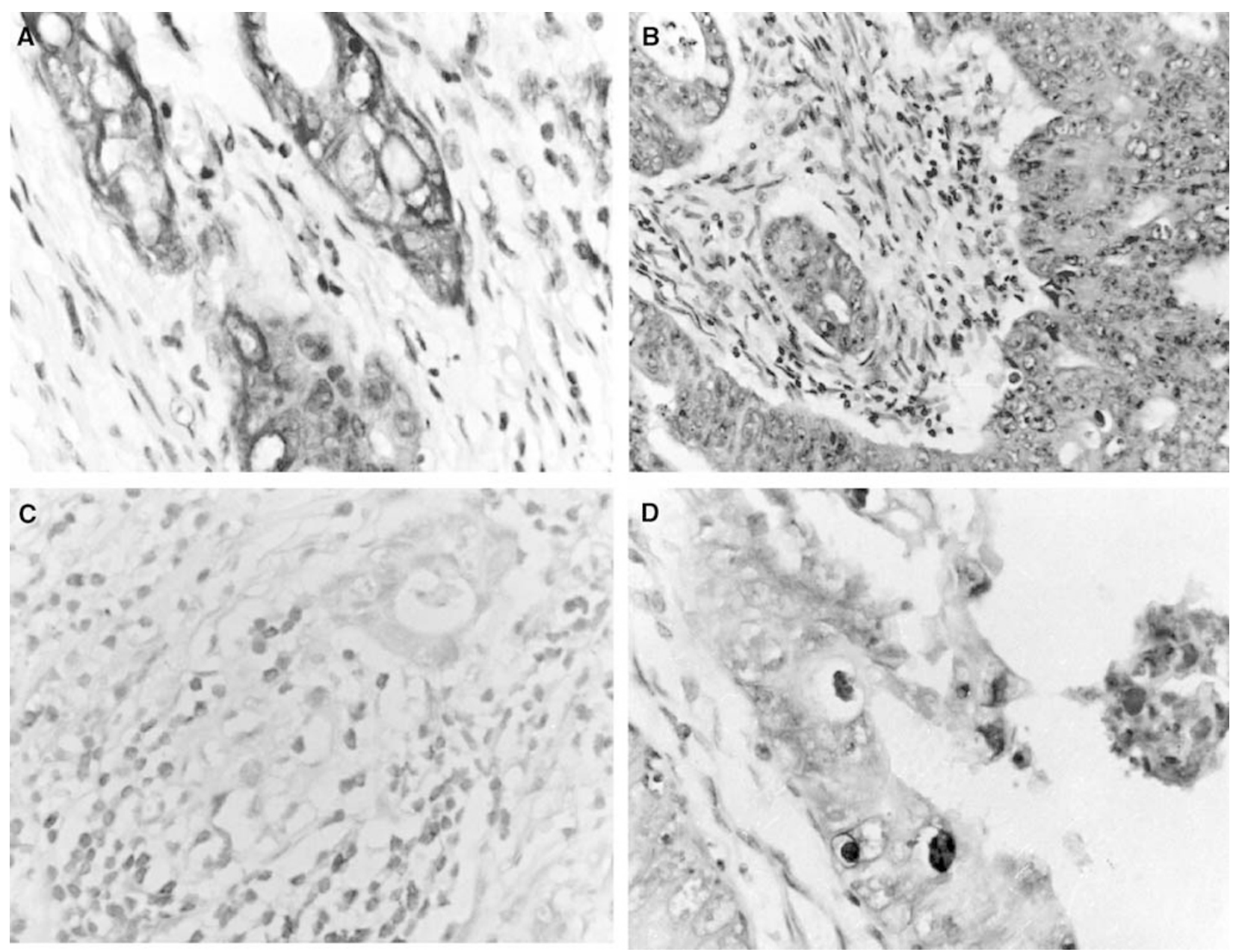

Figure I Immunohistochemical examination of FAP-I, FasR and FasL expression and TUNEL staining in human colon adenocarcinomas. Antibodies were detected using a DAB method that produces a brown colour. Counterstaining of nuclei with haematoxylin (blue). (A) FAP-I-positive immunohistochemical staining in the cytoplasm of colon adenocarcinoma cells. (B) FasR-positive immunohistochemical staining in the cytoplasm of colon adenocarcinoma cells. (C) FasL-positive immunohistochemical staining in the cytoplasm of TILs. (D) TUNEL staining in apoptotic colon adenocarcinoma cells. Only those cells with positive TUNEL staining and exhibiting apoptotic morphology were considered apoptotic.

observed in cultured tumour cells of the eight cases of colon cancers without FAP-1 immunostaining (FasR-sensitive group) (Figure 3A).

The percentage of cell death was elevated to $11.19 \pm 4.04$ at $10 \mathrm{ng} \mathrm{ml}^{-1}$ of $\mathrm{CH}-11$, which was significantly higher with control antibody $(P<0.05)$, and reached $27.63 \pm 7.08$ at a concentration of $500 \mathrm{ng} \mathrm{ml}^{-1}$ of $\mathrm{CH}-11$. However, higher doses of $\mathrm{CH}-11$ (to $1000 \mathrm{ng} \mathrm{ml}^{-1}$ ) did not result in a further increase of tumour cell apoptosis $(P>0.05)$. In contrast, the percentage of apoptotic tumour cells in the other 20 cases of colon cancers with FAP-1 immunostaining remained stable despite increasing $\mathrm{CH}-11$ concentrations (FasR-refractory group). Even in the presence of $1000 \mathrm{ng} \mathrm{ml}^{-1} \mathrm{CH}-11$, the percentage of apoptotic cancer cells in this group was $3.82 \pm 1.36$, which was not significantly different from treatment with control antibody $(4.12 \pm 1.53 ; P>0.05)$.

\section{FAP-1 expression levels in colon cancer cells}

To confirm the difference of FAP-1 expression levels between the FasR-sensitive and FasR-refractory group, we quantified protein and mRNA expression of FAP-1 in cultured cancer cells by flow cytometric immunofluorescence analysis and RT-PCR. As shown by flow cytometric immunofluorescence analysis, FAP-1 protein was strongly expressed by colon cancer cells of the FasR-refractory group ( $n=20$; RFI $=38.62 \pm 5.82$ ), which showed positive immunostaining with FAP-1 antibody in tissue sections (Figure 4A). In contrast, only a limited amount of FAP-1 protein was detected in tumour cells of the FasR-sensitive group $(n=8 ; \mathrm{RFI}=5.1 \pm 1.8)$, which was significantly lower than that of the FasR-refractory group $(P<0.01) \quad$ (Figure 4B). Similarly, FAP-1 mRNA was abundantly expressed by tumour cells from the FasR-refractory group, while a much weaker expression of FAP-1 mRNA was observed in the Fas-sensitive group (Figure 5). Semiquantification of RT-PCR results revealed that the relative amount of FAP-1 mRNA in the Fas-refractory group $(n=20 ; 1.82 \pm 0.63)$ was significantly higher than in the Fas-sensitive group $(n=8$; $0.37 \pm 0.19)(P<0.01)$.

\section{Inhibition of FasR resistance by Ac-SLV}

To further investigate whether FAP-1 expression did contribute to the FasR refractory property of colon cancer cells, we blocked the interaction between FAP-1 and FasR. Before treatment with $\mathrm{CH}-11$ $\mathrm{mAb}$, cultured tumour cells were preincubated with Ac-SLV. AcSLV has the same amino-acid sequence as the C-terminal end of FasR. Thus, Ac-SLV competes with FasR for the binding to FAP-1 

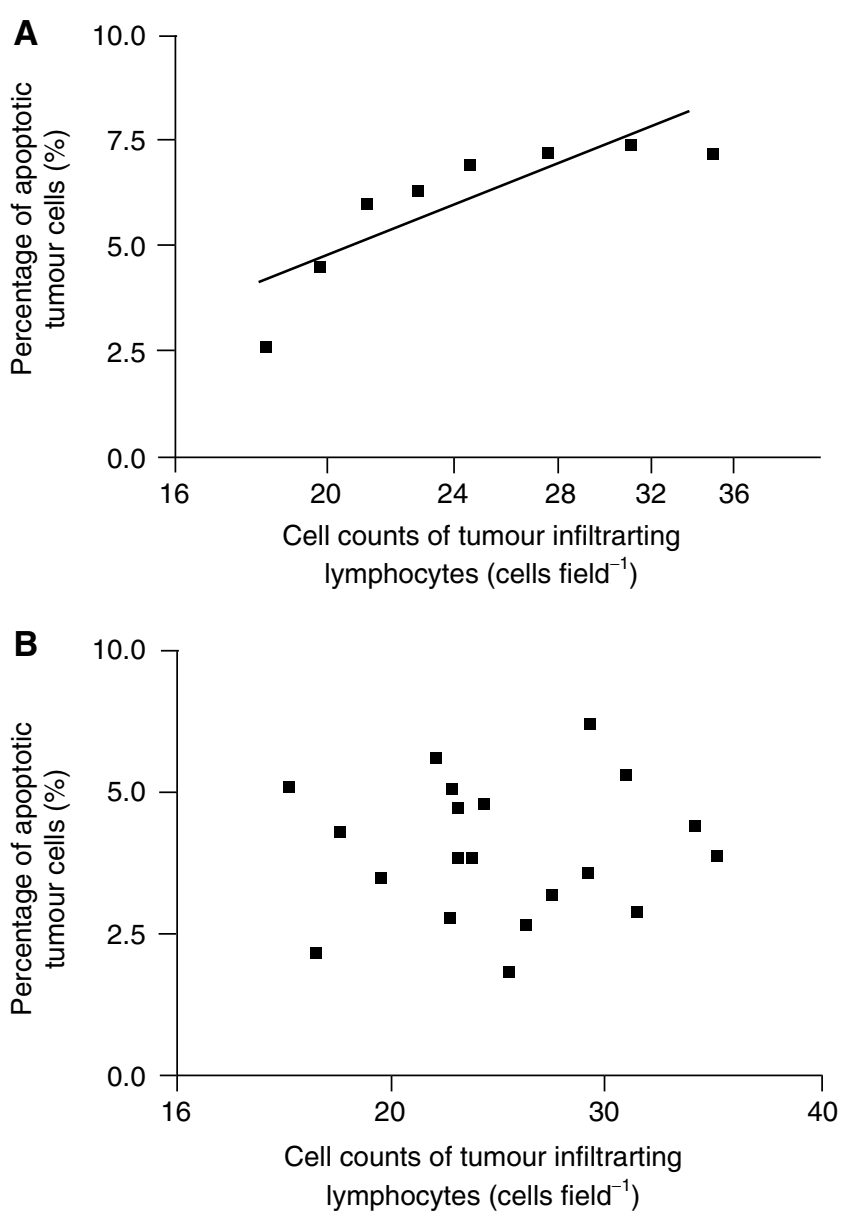

Figure 2 Correlation between the percentage of in situ apoptotic colon adenocarcinoma cells and the number of FasL-positive TILs. (A) In FAP-I negative colon cancers, a linear correlation was observed between the percentage of apoptotic tumour cells and the log value of FasL-positive TIL counts $(r=0.835, P<0.01)$. (B) In FAP-I-positive colon cancers, the percentage of apoptotic tumour cells was not correlated to FasL-positive TIL counts.

(Yanagisawa et al, 1997; Sawa et al, 1999), prominently enhancing FasR sensitivity of colon cancer cells in the FasR-refractory group. It also increased the number of apoptotic tumour cells after incubation with $\mathrm{CH}-11$ in a dose-dependent manner (Figure 3B). The percentage of apoptotic cancer cells from the FasR-refractory group pretreated with Ac-SLV was $9.91 \pm 3.83$ in the presence of $10 \mathrm{ng} \mathrm{ml}^{-1} \mathrm{CH}-11$, which was significantly higher than in controls $(P<0.05)$, and reached $26.72 \pm 8.2$ when the concentration of $\mathrm{CH}-$ 11 was increased to $500 \mathrm{ng} \mathrm{ml}^{-1}$. However, a concentration of $1000 \mathrm{ng} \mathrm{ml}^{-1}$ of $\mathrm{CH}-11$ did not increase in apoptosis of colon cancer cells any further $(P>0.05)$.

On the other hand, treatment with Ac-SLV alone did not increase the apoptosis of colon cancer cells (Figure 3B).

Furthermore, preincubation with Ac-SLV did not affect the apoptosis of colon cancer cells from the FasR-sensitive group significantly in the presence of $\mathrm{CH}-11$ at different concentrations (data not shown).

\section{DISCUSSION}

The present study demonstrated a high incidence of FAP-1 expression $(71 \%)$ in colon carcinomas in the presence of Fas receptors. Moreover, FAP-1-expressing colon cancer cells were

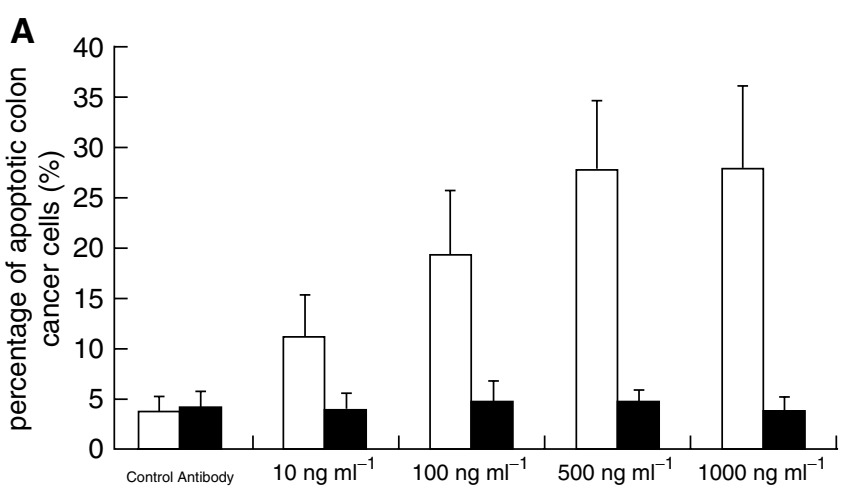

Concentration of agonistic anti-FasR antibody $\mathrm{CH}-11\left(\mathrm{ng} \mathrm{ml}^{-1}\right)$

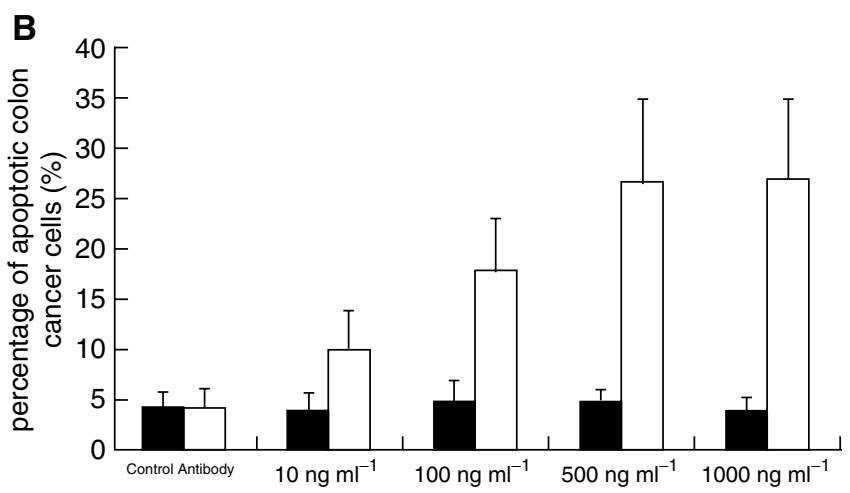

Concentration of agonistic anti-FasR MoAb CH-11(ng ml${ }^{-1}$ )

Figure 3 Percentage of apoptotic cultured colon cancer cells in the presence of different concentrations of $\mathrm{CH}-\mathrm{II}$. (A) When the concentration of $\mathrm{CH}$ - I I increased up to $500 \mathrm{ng} \mathrm{ml}^{-1}$, a dose-dependent increase of the apoptotic percentage of cultured colon cancer cells was observed in those cases without FAP-I expression ( $\square$, Fas-sensitive group; $n=8$, $P<0.05$ ), while the ones in the cases with FAP-I expression ( $\boldsymbol{\square}$, Fasrefractory group; $n=20)$ remained stable $(P>0.05)$. However, further elevation of $\mathrm{CH}$ - I I concentration from 500 to $1000 \mathrm{ng} \mathrm{ml}^{-1}$ did not result in a further increment of tumour cell apoptosis in Fas-sensitive group $(P>0.05)$. (B) After preincubation with Ac-SLV, cultured colon cancer cells of Fas-refractory group showed a dose-dependent increase of the apoptotic percentage with the increase of $\mathrm{CH}$ - I I concentration up to $500 \mathrm{ng} \mathrm{ml}^{-1}(\boldsymbol{\square})(P<0.05)$ in contrast to untreated ones $(\square)$. Further elevation of $\mathrm{CH}$ - I | concentration from 500 to $1000 \mathrm{ng} \mathrm{ml}^{-1}$ did not result in a further increment of tumour cell apoptosis $(P>0.05)$. Ac-SLV alone did not increase apoptosis of tumour cells when treated with control antibody $(P>0.05)$.

refractory to FasR-mediated apoptosis. This resistance could be reversed by blockade of FAP-1 and FasR interaction with an interacting tripeptide Ac-SLV.

It has been demonstrated in vitro and in vivo that colon cancer cells coexpress Fas receptors and functional FasLs on their cell surface (Houghton et al, 1997; Ding et al, 1998; Krammer et al, 1998; O'Connell et al, 1998; Peduto et al, 1999; Yoong et al, 1999; Vermijlen et al, 2001). Thus, it was not surprising that Fas receptor was expressed in all cases of colon carcinomas to some extent. Approximately $61 \%$ of colon cancers coexpressed FasL. A recent study has also reinforced the notion that colon cancers are resistant to FAS-mediated apoptosis (Houston et al, 2003). Furthermore, like in other malignancies (O'Connell et al, 1999; Fukuzawa et al, 2001; Meech et al, 2001), FasL-positive TILs were found in all cases of colon cancer in our study, which probably represented the local immune response of hosts against tumours. As activated CTLs and NK cells can express FasL and induce apoptosis in Fas-bearing cells, it is unclear as to why Fas-bearing 

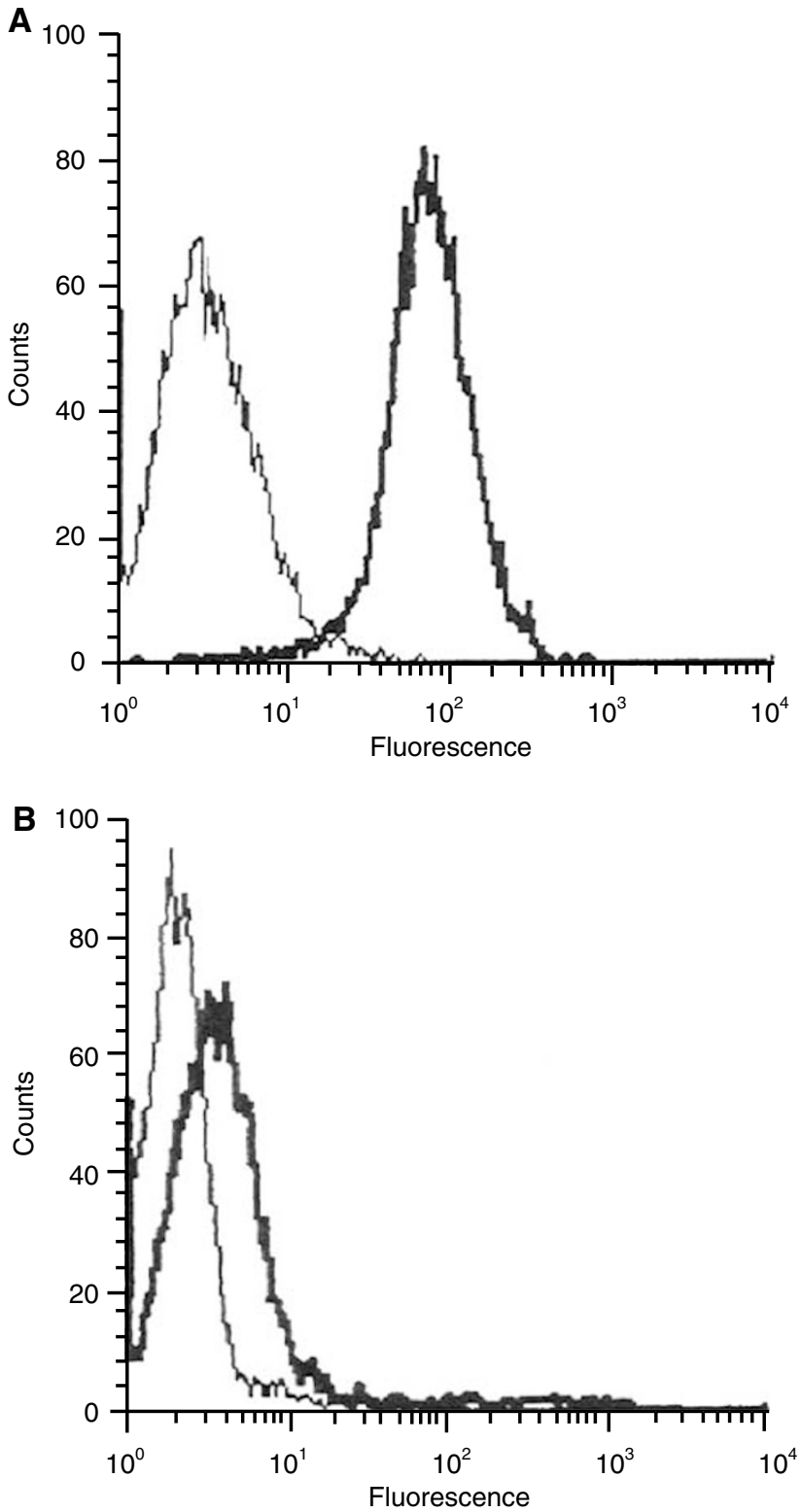

Figure 4 Flow cytometric analysis of FAP-I expression on cultured colon cancer cells of Fas-refractory group $(\mathbf{A})$ and Fas-sensitive group $(\mathbf{B})$ using polyclonal anti-FAP-I antibody (bold peaks) or an irrelevant antibody (isotype control) for the determination of background staining (thin-line peaks).

cancer cells are not destroyed by TILs, which express FasL, and why colon cancer cells do not undergo apoptosis via Fas and FasL interaction.

Presently, the exact mechanisms by which colon cancer cells escape from FasL-induced apoptosis are not fully understood. Some authors hypothesised that colon cancer cells are resistant to FasR-mediated apoptosis due to the presence of inhibitory proteins in the Fas signal transduction pathway (Ding et al, 1998; Krammer et al, 1998; O'Connell et al, 1998; Yoong et al, 1999; Vermijlen et al, 2001). A possible candidate is FAP-1 because activation and dysregulation of the FAP-1 promoter has been demonstrated in human colon carcinoma cell line in vitro (Irie et al, 2001). We examined this hypothesis by investigating the role of FAP-1 as an inhibitor in FasR-mediated apoptosis of colon cancer cells.

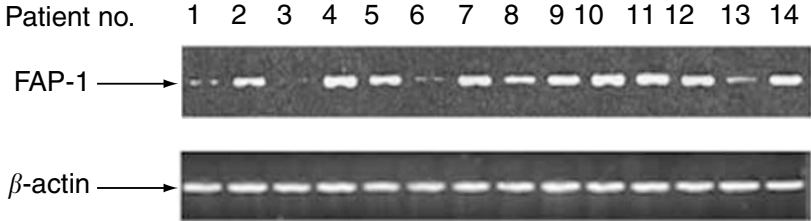

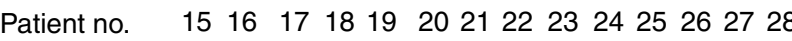

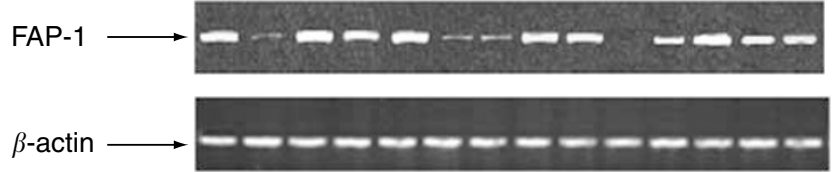

Figure 5 RT-PCR analysis of FAP-I mRNA expression in cultured colon cancer cells. Patients no. I, 3, 6, 13, 16, 20, 21, and 24 belonged to the Fas-sensitive group (sensitive to $\mathrm{CHI}$ I-induced apoptosis; $n=8$ ), while the rest belonged to Fas-refractory group (resistant to $\mathrm{CHI}$-induced apoptosis; $n=20$ ).

Using immunohistochemistry, we demonstrated FAP-1 expression in more than $70 \%$ of colon cancers, concurring with the immunohistochemical localisation of FAP-1 in a large panel of cancers of various origins, including colon, lung, and breast carcinomas, reported by Lee et al (1999b). Additionally, FAP-1 immunostaining, herein, was observed along the cell membrane and/or in the cytosol, suggesting a possible role for FAP-1 to interact with the cytosolic domain of Fas just beneath the cell membrane (Ungefroren et al, 1999). This hypothesis was further supported by the present findings that colon cancers with FAP-1 expression had fewer apoptotic tumour cells in comparison to the ones without such expression. Furthermore, in colon cancers with FAP-1 expression, the percentage of apoptotic colon cancer cells, which bore FasR on their surface, did not correlate with the number of FasL-positive TILs surrounding the tumour nests. In contrast, the percentage of apoptotic colon cancer cells in tissue sections revealed a positive correlation with the FasL-positive TIL counts. The correlation was more pronounced when the level of FasL-positive TIL counts was in the lower range. This suggests that the sensitivity of colon cancer cells to FasR-mediated apoptosis depends on in vivo FAP-1 expression. In vivo expression of FAP-1 was also suggested to be a possible mechanism for Fas resistance in human hepatoblastomas by Lee et al (1999b).

Although FAP-1 has been suggested to interact with the 'suppressive domain' of Fas receptor that is involved in the inhibition of the apoptotic signal (Ungefroren et al, 2001), no direct proofs exists for the contribution of FAP-1 expression to FasR resistance in colon cancer cells. Hence, we performed primary cultures of colon cancer cells on our samples, and treated them with $\mathrm{CH} 11$, an agonistic Fas $\mathrm{mAb}$, in order to demonstrate directly the influence of FAP-1 expression on FasR sensitivity. In consistence with our in vivo evaluation, our data demonstrated a dose-dependent increase in the amount of apoptosis induced by $\mathrm{CH}-11$ in colon cancer cells in parallel to a reduced expression of FAP-1 mRNA and protein.

On the other hand, despite exposure to a high dose of $\mathrm{CH}-11$ (1000 $\mathrm{ng} \mathrm{ml}^{-1}$ ), colon cancer cells, which had pronounced FAP-1 expression at mRNA and protein levels, were irresponsive to FasRmediated apoptosis. These data are in line with a recent finding on a pancreatic cancer cell line, showing that FAP-1-expressing pancreatic cancer cells were resistant to Fas-mediated apoptosis (Ungefroren et al, 1999).

Furthermore, treatment with Ac-SLV tripeptide abrogated the resistance of Fas-mediated apoptosis in FAP-1-expressing colon cancer cells, as apoptosis was induced in these cells by $\mathrm{CH}-11$ in a 
dose-dependent manner. Ac-SLV shares the C-terminal three amino acids (SLV) with FasR. This sequence is necessary and sufficient to interact with FAP-1 (Moulian et al, 1999). Thus, AcSLV can competitively prevent the interaction of FAP-1 with Fas and results in the induction of Fas-mediated apoptosis (Yanagisawa et al, 1997; Sawa et al, 1999). Similarly, application of Ac-SLV in thyroid follicular cells has also been found to enhance Fasmediated apoptosis (Myc et al, 1999). In this context, the present inhibition of Ac-SLV of FasR resistance in colon cancer cells substantiates our hypothesis that FAP-1 is an inhibitor of Fasmediated apoptosis in colon cancer cells.

Interestingly, in colon cancers without FAP-1 expression, the percentage of apoptotic tumour cells was positively correlated to the logarithmic value of FasL-positive TIL count.

Likewise, even when the interaction between FasR and FAP-1 was blocked, agonistic anti-Fas mAb enhanced apoptosis in primarily cultured tumour cells in a dose-dependent manner up to a concentration of $500 \mathrm{ng} \mathrm{ml}^{-1}$. This suggests that, in addition to FAP-1 expression, there are other factors in the Fas signalling pathway that can influence celluar sensitivity to Fas-mediated apoptosis in colon cancer cells, for example, reduction of Fas receptor levels on colon cancer cells (Butler et al, 2000; Song et al, 2001b), release of soluble Fas (Cheng et al, 1994) or decoy receptor (Pitti et al, 1998) for FasL that blocks FasL on CTLs, mutation or

\section{REFERENCES}

Arase H, Arase N, Saito T (1995) T Fas-mediated cytotoxicity by freshly isolated natural killer cells. J Exp Med 181: 1235-1238

Beatty GL, Paterson Y (2000) IFN-gamma can promote tumor evasion of the immune system in vivo by down-regulating cellular levels of an endogenous tumor antigen. J Immunol 165: 5502-5508

Bernhard D, Skvortsov S, Tinhofer I, Hubl H, Greil R, Csordas A, Kofler R (2001) Inhibition of histone deacetylase activity enhances Fas receptor-mediated apoptosis in leukemic lymphoblasts. Cell Death Differ 8: $1014-1021$

Butler LM, Dobrovic A, Bianco T, Cowled PA (2000) Promoter region methylation does not account for the frequent loss of expression of the Fas gene in colorectal carcinoma. Br J Cancer 82: 131-135

Cheng J, Zhou T, Liu C, Shapiro JP, Brauer MJ, Kiefer MC, Barr PJ, Mountz JD (1994) Protection from Fas-mediated apoptosis by a soluble form of the Fas molecule. Science 263: 1759-1762

Ding EX, Hizuta A, Morimoto Y, Tanida T, Hongo T, Ishii T, Yamano T, Fujiwara T, Iwagaki H, Tanaka N (1998) Human colon cancer cells express the functional Fas ligand. Res Commun Mol Pathol Pharmacol 101: $13-24$

Fukuzawa K, Takahashi K, Furuta K, Tagaya T, Ishikawa T, Wada K, Omoto Y, Koji T, Kakumu S (2001) Expression of fas/fas ligand (fasL) and its involvement in infiltrating lymphocytes in hepatocellular carcinoma (HCC). J Gastroenterol 36: 681-688

Grosch S, Tegeder I, Niederberger E, Brautigam L, Geisslinger G (2001) COX2 independent induction of cell cycle arrest and apoptosis in colon cancer cells by the selective COX-2 inhibitor celecoxib. FASEB J 15: 2742-2744

Halapi E (1998) Oligoclonal T cells in human cancer. Med Oncol 15: $203-211$

Houghton JA, Harwood FG, Gibson AA, Tillman DM (1997) The fas signaling pathway is functional in colon carcinoma cells and induces apoptosis. Clin Cancer Res 3: 2205-2209

Houston A, Waldron-Lynch FD, Bennett MW, Roche D, O'Sullivan GC, Shanahan F, O'Connell J (2003) Fas ligand expressed in colon cancer is not associated with increased apoptosis of tumor cells in vivo. Int J Cancer 107: 209-214

Irie S, Li Y, Kanki H, Ohyama T, Deaven LL, Somlo S, Sato TA (2001) Identification of two Fas-associated phosphatase-1 (FAP-1) promoters in human cancer cells. DNA Sequence 11: 519-526

Itakura M, Mori S, Park NH, Bonavida B (2000) Both HPV and carcinogen contribute to the development of response to apoptosis during oral carcinogenesis. Int J Oncol 16: 591 - 597

Itoh N, Nagata S (1993) A novel protein domain required for apoptosis. J Biol Chem 268: $10932-10937$ modification of an essential signalling molecule of the Fas signaling pathway (Itoh and Nagata, 1993), and increased expression of BCL-2 gene (Meterissian and Kontogiannea, 1996). Hence, further studies are needed to elucidate the complete pathway of Fas signaling processes in generating apoptotic responses in colon carcinomas.

In conclusion, the present study suggests that FAP-1 expression contributes to the resistance of colon cancer cells to Fas-mediated apoptosis and, thus, is involved in immune escape from CTLs and NK cells. These effects may be abolished by a blockade of the interaction of FAP-1 with FasR.

\section{ACKNOWLEDGEMENTS}

This work was supported in part by a National Scientific Research Grant of People's Republic of China and a Provincial Natural Scientific Research Grant from Guangdong, People's Republic of China. P Hamar is a recipient of Békésy Scolarship of the Hungarian Ministry of Education (OM: BÖ 121/2001). Further support was provided by the intergovernmental cooperation funding between China and Hungary (MT1:21/China-OMFB/ CHN 10-03/Hungary).

Kägi D, Vignaux F, Ledermann B, Bürki K, Depraetere V, Nagata S, Hengartner H, Golstein P (1994) Fas and perforin pathways as major mechanisms of T cell-mediated cytotoxicity. Science 265: 528-530

Krammer PH, Galle PR, Möller P, Debatin KM (1998) CD95(APO-1/Fas)mediated apoptosis in normal and malignant liver, colon, and hematopoietic cells. Adv Cancer Res 75: 251-273

Lee SH, Shin MS, Lee JY, Park WS, Kim SY, Jang JJ, Dong SM, Na EY, Kim CS, Kim SH, Yoo NJ (1999a) In vivo expression of soluble Fas and FAP-1: possible mechanism for Fas resistance in human hepatoblastomas. J Pathol 188: $207-212$

Lee SH, Shin MS, Park WS, Kim SY, Kim HS, Lee JH, Han SY, Lee HK, Park JY, Oh RR, Jang JJ, Lee JY, Yoo NJ (1999b) Immunohistochemical localization of FAP-1, an inhibitor of Fas-mediated apoptosis, in normal and neoplastic human tissues. APMIS 107: $1101-1108$

Leithauser F, Dhein J, Mechtersheimer G, Koretz K, Bruderlein S, Henne C, Schmidt A, Debatin KM, Krammer PH, Moller P (1993) Constitutive and induced expression of APO-1, a new member of the nerve growth factor/ tumor necrosis factor receptor superfamily, in normal and neoplastic cells. Lab Invest 69: 415-429

Lowin B, Hahne M, Mattmann C, Tschopp J (1994) Cytolytic T-cell cytotoxicity is mediated through perforin and Fas lytic pathways. Nature 370: $650-652$

Meech SJ, Edelson R, Walsh P, Norris DA, Duke RC (2001) Reversible resistance to apoptosis in cutaneous T cell lymphoma. Ann NY Acad Sci 941: $46-58$

Meterissian S, Kontogiannea M (1996) Fas antigen expression and function in human colorectal carcinoma: correlation with Bcl-2 expression. Proc Am Assoc Cancer Res 37: 15-23

Moulian N, Renvoize C, Desodt C, Serraf A, Berrih-Aknin S (1999) Functional Fas expression in human thymic epithelial cells. Blood 93: $2660-2670$

Myc A, Arscott PL, Bretz JD, Thompson NW, Baker JR (1999) Characterization of FAP-1 expression and function in thyroid follicular cells. Endocrinology 140: $5431-5434$

Nagata S (1997) Apoptosis by death factor. Cell 88: 355-365

O'Connell J, Bennett MW, O'Sullivan GC, O'Callaghan J, Collins JK, Shanahan F (1999) Expression of Fas (CD95/APO-1) ligand by human breast cancers: significance for tumor immune privilege. Clin Diagn Lab Immunol 6: $457-463$

O'Connell J, Bennett MW, O’Sullivan GC, Roche D, Kelly J, Collins JK, Shanahan F (1998) Fas ligand expression in primary colon adenocarcinomas: evidence that the Fas counterattack is a prevalent mechanism of immune evasion in human colon cancer. J Pathol 186: 240-246 
Peduto L, Guillou L, Saraga E, Schroter M, French LE, Tschopp J, JuilleratJeanneret L (1999) Fas and Fas ligand expression in tumor cells and in vascular smooth-muscle cells of colonic and renal carcinomas. Int $J$ Cancer 81: $772-778$

Pitti RM, Marsters SA, Lawrence DA, Roy M, Kischkel FC, Dowd P, Huang A, Donahue CJ, Sherwood SW, Baldwin DT, Godowski PJ, Wood WI, Gurney AL, Hillan KJ, Cohen RL, Goddard AD, Botstein D, Ashkenazi A (1998) Genomic amplification of a decoy receptor for Fas ligand in lung and colon cancer. Nature 396: 699-703

Sawa E, Takahashi M, Kamishohara M, Tazunoki T, Kimura K, Arai M, Miyazaki T, Kataoka S, Nishitoba T (1999) Structural modification of Fas C-terminal tripeptide and its effect in the inhibitory activity of Fas/FAP-1 binding. J Med Chem 42: 3289-3299

Song E, Chen J, Ouyang N, Su F, Wang M, Heemann U (2001a) Soluble Fas ligand released by colon adenocarcinoma cells induces host lymphocyte apoptosis: an active mode of immune evasion in colon cancer. $\mathrm{Br} J$ Cancer 85: 1047 - 1054

Song E, Chen J, Ouyang N, Wang M, Exton MS, Heemann U (2001b) Kupffer cells of cirrhotic rat livers sensitize colon cancer cells to Fasmediated apoptosis. Br J Cancer 84: $1265-1271$

Suda T, Nagata S (1994) Purification and characterization of the Fas-ligand that induces apoptosis. J Exp Med 179: $873-879$

Suda T, Takahashi T, Golstein P, Nagata S (1993) Molecular cloning and expression of the Fas ligand, a novel member of the tumor necrosis factor family. Cell 75: $1169-1178$
Tillman DM, Harwood FG, Gibson AA, Houghton JA (1998) Expression of genes that regulate Fas signalling and Fas-mediated apoptosis in colon carcinoma cells. Cell Death Differ 5: $450-457$

Ungefroren H, Kruse ML, Trauzold A, Roeschmann S, Roeder C, Arlt A, Henne-Bruns D, Kalthoff H (2001) FAP-1 in pancreatic cancer cells: functional and mechanistic studies on its inhibitory role in CD95mediated apoptosis. J Cell Sci 114: 2735-2746

Ungefroren H, Voss M, Bernstorff WV, Schmid A, Kremer B, Kalthoff H (1999) Immunological escape mechanisms in pancreatic carcinoma. Ann NY Acad Sci 880: $243-251$

Vermijlen D, Froelich CJ, Luo D, Suarez-Huerta N, Robaye B, Wisse E (2001) Perforin and granzyme B induce apoptosis in FasL-resistant colon carcinoma cells. Cancer Immunol Immunother 50: $212-217$

von Reyher U, Strater J, Kittstein W, Gschwendt M, Krammer PH, Moller P (1998) Colon carcinoma cells use different mechanisms to escape CD95mediated apoptosis. Cancer Res 58: 526-534

Yanagisawa J, Takahashi M, Kanki H, Yano-Yanagisawa H, Tazunoki T, Sawa E, Nishitoba T, Kamishohara M, Kobayashi E, Kataoka S, Sato T (1997) The molecular interaction of Fas and FAP-1. A tripeptide blocker of human Fas interaction with FAP-1 promotes Fas-induced apoptosis. J Biol Chem 272: 8539-8545

Yoong KF, Afford SC, Randhawa S, Hubscher SG, Adams DH (1999) Fas/ Fas ligand interaction in human colorectal hepatic metastases. Am J Pathol 154: $693-703$ 